\title{
Rapid identification and detection of Vibrio parahaemolyticus via different types of modus operandi with LAMP method in vivo
}

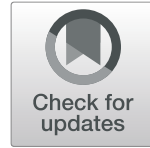

\author{
Jun $\mathrm{Li}^{1 \dagger}$, Jianfei $\mathrm{Liu}^{2 \dagger}$, Kaifei Fu${ }^{2}$, Kewei Qin², Chenglin $\mathrm{Wu}^{2}$, Xiaojie $\mathrm{Yu}^{2}$, Shan Zhou ${ }^{1 *}$ and Lijun Zhou ${ }^{2 *}$
}

\begin{abstract}
Purpose: Vibrio parahaemolyticus, an easy-ignored food-borne pathogen, can cause bacterial outbreaks and human disease during early-stage infection. In this study, we aimed to evaluate the detection efficiency of loop-mediated isothermal amplification (LAMP) as an emerging technique to directly detect $V$. parahaemolyticus infection in mammalian hosts and assess its potential in clinical applications.

Methods: A LAMP assay was used for rapid identification of $V$. parahaemolyticus in a variety of mouse models in which animals were infected via the digestive tract, wounds, or through general infection, and the results were compared with routine analytical methods.

Results: Our results confirmed that the LAMP assay was capable of detecting $V$. parahaemolyticus in different mouse organs independent of the source of bacteria, although its sensitivity depended on the route of infection and the organ affected. Foodborne-derived $V$. parahaemolyticus was the most sensitive route, with the small intestine being the most sensitive organ. The LAMP assay indicated that $V$. parahaemolyticus that spread through the blood stream had the most serious consequences during early-stage infection. Positive LAMP results were identified in all blood samples from i.V. injected mice. Furthermore, the LAMP method could directly detect trace quantities of $V$. parahaemolyticus in fresh peripheral blood while conventional methods failed to do so, thereby shortening the time-to-result from days to minutes. Conclusions: In this study, we demonstrated that the LAMP assay was effective in speeding up the detection of $V$. parahaemolyticus. Instead of being a secondary method to assist in the clinic, the LAMP assay has potential for use as the primary technique for rapid detection of $V$. parahaemolyticus in the future.
\end{abstract}

Keywords: Detection in vivo, LAMP, Mouse model, Vibrio parahaemolyticus

\section{Background}

Vibrio parahaemolyticus is a common gram-negative $\left(\mathrm{G}^{-}\right)$ halophilic bacterial species that is principally distributed within sea water (DePaola et al. 1990), coastal areas, and river-sea junctures (Yang et al. 2017a). It can also be found in seafood (Twedt 1989; Rince et al. 2018). In addition to

\footnotetext{
*Correspondence: nghzhoushan@163.com; hzzhoulj@126.com

${ }^{\dagger} J u n$ Li and Jianfei Liu contributed equally to this work.

'Department of Medical Service, The Sixth Medical Centre, Chinese PLA

(People's Liberation Army) General Hospital, Beijing, People's Republic of China

${ }^{2}$ Central Laboratory, The Sixth Medical Centre, Chinese PLA (People's Liberation Army) General Hospital, Beijing, People's Republic of China
}

its presence in marine environments, $V$. parahaemolyticus can also be found in livestock and poultry meat, freshwater fish, preserved eggs, and pickles (Barker 1974). Therefore, despite the sources of marine infection, such as seafood and marine salts, a variety of animal species can also be carriers of $V$. parahaemolyticus, rendering it an important pathogenic bacterium that is highly infectious.

Human infection with $V$. parahaemolyticus is an important public health problem (Baker-Austin et al. 2018). V. parahaemolyticus is the principal pathogen causing acute gastroenteritis in humans via consumption of infected seafood, for which the symptoms include stomachache (Liu et al. 2015), diarrhea (Gong et al.

(c) The Author(s). 2020 Open Access This article is licensed under a Creative Commons Attribution 4.0 International License, which permits use, sharing, adaptation, distribution and reproduction in any medium or format, as long as you give appropriate credit to the original author(s) and the source, provide a link to the Creative Commons licence, and indicate if changes were made. The images or other third party material in this article are included in the article's Creative Commons licence, unless indicated otherwise in a credit line to the material. If material is not included in the article's Creative Commons licence and your intended use is not permitted by statutory regulation or exceeds the permitted use, you will need to obtain permission directly from the copyright holder. To view a copy of this licence, visit http://creativecommons.org/licenses/by/4.0/. 
2018), vomiting, dehydration, chills, and fever (Raszl et al. 2016). In the USA, V. parahaemolyticus is the leading cause of human gastroenteritis and associated with seafood consumption (Park et al. 2018). In coastal Asian countries, including Indonesia, $V$. parahaemolyticus is the leading cause of bacterial foodborne infections (Lesmana et al. 2001; Lee et al. 2018). In Japan, food poisoning caused by $V$. parahaemolyticus accounts for $20 \sim 30 \%$ of all cases of human food poisoning (Alam et al. 2002). In Europe and North America, many outbreaks of $V$. parahaemolyticus food poisoning have been reported (McLaughlin et al. 2005; Martinez-Urtaza et al. 2013; Martinez-Urtaza et al. 2016). Coincidentally, over the past two decades, published reports have indicated that $V$. parahaemolyticus has been the principal cause of bacterial foodborne infections in China (Li et al. 2014). According to the continuously monitoring data from 2013 mainland China from the National Foodborne Disease Outbreaks Surveillance System (NFDOSS), V. parahaemolyticus was the leading factor causing $27.8 \%$ of all the microbial-driven foodborne disease outbreaks, making it the only marine bacterial species among the 5 most common pathogens, and the 5th most common species found in food (Li et al. 2018).

In southern China, there is a strong seasonal pattern in the outbreaks of human infection by $V$. parahaemolyticus, which partially attributes to the different carriage rate of marine products throughout the year. In a study by Yang et al., investigating 504 seafood samples from 11 provinces of China, it was shown that the prevalence of $V$. parahaemolyticus peaked during the summer $(33 \%)$ and reduced by half during the winter (14\%) in fish, oyster, and shrimp (Yang et al. 2017b). The disease caused by $V$. parahaemolyticus can spread widely but with generally mild symptoms, which are usually selflimiting (Rizvi and Bej 2010), possibly causing people to pay little attention to it. Due to symptoms resulting from $V$. parahaemolyticus, infections similar to that by other common food-borne pathogens make the prevention of $V$. parahaemolyticus infection and its early-stage medical treatment easily be neglected.

With the development of technology, methods of $V$. parahaemolyticus detection have increased. To meet improved diagnostic accuracy, culture medium for conventional phenotypes and biochemical identification methods has undergone a process of constant improvement from standard alkaline peptone water (APW) to ST medium, thiosulfate citrate bile salts sucrose agar culture medium (TCBS) or Wagatsuma agar (MartinezUrtaza et al. 2006; Croci et al. 2007; Letchumanan et al. 2014). The CHROMagar Vibrio medium is gradually being applied in the clinic and significantly improves interpretation. Nevertheless, conventional methods still face the obstacles of time- and labor-intensive methodology.
With the advent of nucleic acid-based methods, such as multiplex PCR, real-time PCR, RAPD-PCR, REP-PCR, ERIC-PCR, GS-PCR, nucleic acid sequence-based amplification (NASBA), fluorescence in situ hybridization (FISH), and micro arrays (Di Pinto et al. 2012; Letchumanan et al. 2014; Nordin et al. 2016; Cho et al. 2017; $\mathrm{Xu}$ et al. 2018), the detection of $V$. parahaemolyticus is becoming more convenient. In addition, biosensor and immunological-based methods have also become available (Kumar et al. 2011). However, these methods are too complex for the detection of $V$. parahaemolyticus in a large number of clinical samples.

Since 2000, loop-mediated isothermal amplification (LAMP) (Notomi et al. 2000) has played a significant role in medical diagnostics, including the diagnosis of clinical diseases (Dea-Ayuela et al. 2018; Waterfield et al. 2018), qualitative detection of epidemic bacteria or viruses, and gender identification of animal embryos (Poon et al. 2004; Fujita et al. 2017; Wong et al. 2018). As an emerging method for the detection of $V$. parahaemolyticus and the rapid diagnosis of infections, LAMP has greatly boosted the capability of detection of earlystage infections. Chen and Ge developed a toxR-based LAMP assay in 2010 (Chen and Ge 2010), and Zhou et al. extended the LAMP assay for $V$. parahaemolyticus identification into field-based detection in 2016 (Zhou et al. 2016). Moreover, Wang et al. optimized the assay in 2016 by developing a multiple endonuclease restriction LAMP method (Wang et al. 2016). However, few reports or systematic studies focused on the rapid detection of early-stage $V$. parahaemolyticus infection in humans using LAMP, and therefore, detailed characteristics of the LAMP assay, such as detection efficiency, sensitivity, and duration, remain unknown.

Based on the rationale described above, in the present study, the LAMP assay was optimized for rapid diagnosis of $V$. parahaemolyticus. Detection efficiency was determined by the detection of $V$. parahaemolyticus infections in a variety of mouse infection models under various conditions. By comparing this LAMP assay with current detection standards, we aimed to establish a more accurate and rapid technique for the detection of $V$. parahaemolyticus infections and provided experimental evidence in support of its use in such diagnostics.

\section{Methods}

\section{Bacteria and growth conditions}

In this study, a total of $71 \mathrm{~V}$. parahaemolyticus strains were used, including 69 food isolates (hereafter referred to as strains $V p$ 1463 1528, $V p$ 4213, $V p$ 4215, $V p$ 11577), a marine isolate ( $V p$ 1A10122), and a type strain (Vp ATCC 17802, Table 1). V. parahaemolyticus food isolates were kindly provided by Professor Shenghui Cui and were isolated from various food samples; $V$. 
Table $1 \mathrm{~V}$. parahaemolyticus used in this study

\begin{tabular}{llll}
\hline Bacterial genus & Strain ID & Source & Type strain \\
\hline V. parahaemolyticus & Vp $1463-1528(n=66)$ & Food samples & No \\
$V$. parahaemolyticus & Vp 4213 & Food sample & No \\
$V$. parahaemolyticus & Vp 4215 & Food sample & No \\
$V$. parahaemolyticus & Vp 11577 & Food sample & No \\
$V$. parahaemolyticus & Vp 1 A 10122 & Seawater isolates & No \\
$V$. parahaemolyticus & Vp ATCC 17802 & Clinical isolates & Yes \\
\hline
\end{tabular}

parahaemolyticus strain $1 \mathrm{~A} 10122$ and 17802 were purchased from the Marine Culture Collection of China (MCCC, Xiamen, China) and American Type Culture Collection (ATCC, VA, USA), respectively. The $V$. parahaemolyticus strains were recovered on $2216 \mathrm{E}$ agar plates (BD Biosciences, NJ, USA) at $35{ }^{\circ} \mathrm{C}$ for $12 \mathrm{~h}$, and routinely cultured in 2216E broth (BD Biosciences, NJ, USA) at $35{ }^{\circ} \mathrm{C}$ with shaking at $180 \mathrm{rpm}$ for $12 \mathrm{~h}$. Dilution or enrichment of cultured $V$. parahaemolyticus strains was performed in $3 \% \mathrm{NaCl}$ APW (Land Bridge Technology, Beijing, China).

A growth curve of $V$. parahaemolyticus was plotted based on the Gompertz model using Vp ATCC 17802 as the reference strain, which calculated and indicated the relationship between $\mathrm{OD}_{600}$ and fresh culture with an isochronous continuous measurement method. After a 9-h culture process (data from 0 to $9 \mathrm{~h}$ ), an equation was established with the $\mathrm{OD}_{600}$ value on the $\mathrm{X}$-axis and the CFU on the Y-axis. The growth curve was fitted based on the optimized Gompertz equation as follows: $Y$ $=3.42 \times 10^{14} \times e^{-e^{-3.26 \times(x-1.53)}}$. A suspension of fresh $V$. parahaemolyticus strain was prepared for the animal experiments based on the above-mentioned equation.

PCR assay for detection of $V$. parahaemolyticus hemolysin The density of the $71 \mathrm{~V}$. parahaemolyticus strains was adjusted to $3 \times 10^{5} \mathrm{CFU} / \mathrm{mL}$, then cultured in $3 \% \mathrm{NaCl}$ APW at $35{ }^{\circ} \mathrm{C}$ with shaking at $180 \mathrm{rpm}$. After culturing for $6 \mathrm{~h}, 1 \mathrm{~mL}$ of the cultures was centrifuged $(10510 \times$ g) to obtain a bacterial pellet, from which genomic DNA was extracted using a DNA extraction kit (Bacterial genomic DNA extraction kit, DP302-02, TIANGEN, Beijing, China). Concentrations of genomic DNA were measured using a NanoDrop 8000 (Thermo Fisher, MA, USA).

Three pairs of primers targeting $t d h$ (GenBank accession No. M10069), trh (GenBank accession No. KP836472.1), and th (GenBank accession No. AY289609) genes were designed for PCR based on the DNA sequences (Table 2) using the Primer premier 5.0 software (PREMIER Biosoft, CA, USA). Each PCR mixture consisted of a final volume of $20 \mu \mathrm{L}$ containing $200 \mathrm{ng}$ of $V$. parahaemolyticus genomic DNA, $400 \mathrm{nM}$ of each primer pair, $10 \mu \mathrm{L}$ of $2 \times$ GoTaq DNA polymerase mix (Promega, WI, USA) and water. PCR was performed as follows: initial denaturation at $94{ }^{\circ} \mathrm{C}$ for 3 min, followed by 30 cycles of denaturation at $94{ }^{\circ} \mathrm{C}$ for $40 \mathrm{~s}$, annealing at $58{ }^{\circ} \mathrm{C}$ for $30 \mathrm{~s}$ and extension at $72{ }^{\circ} \mathrm{C}$ for 1 min, followed by a final extension at $72{ }^{\circ} \mathrm{C}$ for $5 \mathrm{~min}$, then storage at $4{ }^{\circ} \mathrm{C}$. The amplified PCR products were separated on Tris-boric acid gels in Tris-boric acid buffer to visualize the band sizes.

\section{Mouse source and feeding conditions}

Balb/C female mice (5 6 week old, 17 18 g) used in this study were purchased from Beijing Vital River Laboratory Animal Technology Co., Ltd. (Beijing, China) and were bred under specific-pathogen-free (SPF) conditions.

\section{Mouse infection model of $V$. parahaemolyticus utilizing various routes of administration}

Based on the growth curve, Vp 1474, Vp1496, Vp1513, $V p 1 \mathrm{~A} 10122$, and $V p A T C C 17802$ were incubated at 35 ${ }^{\circ} \mathrm{C}$ with shaking at $180 \mathrm{rpm}$ until the culture had reached an $\mathrm{OD}_{600}$ value of 0.35 (approximately $1.5 \times 10^{6} \mathrm{CFU}$ ). The cell pellet was rinsed once with pre-cooled PBS, then centrifuged for $5 \mathrm{~min}$ at $950 \times \mathrm{g}$ and $4{ }^{\circ} \mathrm{C}$, after which the supernatant was discarded. The cell pellet was resuspended in $100 \mu \mathrm{L}$ of pre-cooled PBS, then stored on ice before their immediate use following the next procedure.

The $V$. parahaemolyticus-localized infection model consisted of the intradermal (i.d.) injection of 5 strains of $V$. parahaemolyticus (approximately $1.5 \times 10^{6} \mathrm{CFU}$ for each strain, $100 \mu \mathrm{L}$ ) into $2 \mathrm{~cm}^{2}$ of skin on the back of each mouse adjacent to the point of attachment of the right leg to the dorsal line following sterilization. Infected mice were then observed for $4 \mathrm{~h}$ for signs of localized inflammation resulting from $V$. parahaemolyticus infection. For the $V$. parahaemolyticus foodborne infection model, 5 strains of $V$. parahaemolyticus (approximately1.5 $\times 10^{6} \mathrm{CFU}$ for each strain, $100 \mu \mathrm{L}$ ) were administered into the stomach of each mouse via intragastric gavage (i.g.), then infected mice were observed for $8 \mathrm{~h}$ to determine the extent of the intestinal inflammation caused by $V$. parahaemolyticus. The wound infection model consisted of the intravenous (i.v.) injection of 5 strains of $V$. parahaemolyticus (approximately1.5 $\times$ $10^{6} \mathrm{CFU}$ for each strain, $100 \mu \mathrm{L}$ ) into the caudal vein of 
Table 2 Pairs of primers targeting on gene $t d h$, trh, and th

\begin{tabular}{|c|c|c|c|c|}
\hline Target & Gene source & Primer name & Sequence $\left(5^{\prime} \rightarrow 3^{\prime}\right)$ & Product length \\
\hline \multirow[t]{2}{*}{$t d h$} & GenBank accession No. M10069 & tdh-F & TTATTGTTGATGTTTACATT & $570 \mathrm{bp}$ \\
\hline & & tdh-R & ATGAAACACCAATATTTTGC & \\
\hline \multirow[t]{2}{*}{ trh } & GenBank accession No. KP836472.1 & trh- $\mathrm{F}$ & CATTTCCGCTCTCATATGC & $250 \mathrm{bp}$ \\
\hline & & trh-R & GGCTCAAAATGGTTAAGCG & \\
\hline \multirow[t]{2}{*}{ th } & GenBank accession No. AY289609 & thh-F & GTTGTTGCTACTTTCTAGCATTTC & $1233 \mathrm{bp}$ \\
\hline & & th-R & GATGAAAAAAACAATCACAC & \\
\hline
\end{tabular}

the sterilized tail of each mouse. Infected mice were observed for $8 \mathrm{~h}$ to ascertain the response to $V$. parahaemolyticus blood infection. In the $V$. parahaemolyticus general infection model, the left abdomen of each mouse was sterilized under the diaphragm, and 5 strains of $V$. parahaemolyticus (approximately1.5 $\times 10^{6} \mathrm{CFU}$ for each strain, $100 \mu \mathrm{L}$ ) were injected intraperitoneally (i.p.) into the abdominal cavity. Infected mice were observed for 8 $\mathrm{h}$ for secondary infection caused by $V$. parahaemolyticus that had spread from the initial site.

\section{Treatment of mouse peripheral blood (MPB) and major organs}

After the period of observation, the mice were anesthetized i.p. using pentobarbital sodium $(50 \mathrm{mg} / \mathrm{kg}, 2 \%$ PBS $\mathrm{v} / \mathrm{v}$ solution). MPB was obtained from the right eye of each mouse and preserved in acid citrate-dextrose (ACD) solution. Mice were then euthanized by cervical dislocation. The whole body of each mouse was sterilized in 75\% ethyl alcohol for $5 \mathrm{~min}$. The target digestive organs, including the stomach, small intestine, and liver, in addition to the kidney (urinary tract), and spleen (immune organ) were removed. Each organ in every group was homogenized using a tissue homogenizer (Servicebio, Wuhan, China).

\section{Subculture of $V$. parahaemolyticus and extraction of genomic DNA}

Ten microliters of homogenates or $10 \mu \mathrm{L}$ of MPB was mixed in $10 \mathrm{~mL}$ of sterile $3 \% \mathrm{NaCl} \mathrm{APW}$ and incubated at $35^{\circ} \mathrm{C}$ for $12 \mathrm{~h}$ with shaking at $180 \mathrm{rpm}$, respectively. A portion of each suspension $(100 \mu \mathrm{L})$ was plated on a TCBS plate. The plates were incubated at $35^{\circ} \mathrm{C}$ for $18 \mathrm{~h}$ to determine $V$. parahaemolyticus colonies.

The remaining MPB was diluted with PBS to $1 \mathrm{~mL}$ and $1 \mathrm{~mL}$ of the enriched suspension from each organ used for DNA extraction using a DNA extraction kit (Genomic DNA extraction kit for blood/cell/tissue, DP304-03, TIANGEN, Beijing, China).

\section{LAMP assay}

The LAMP-based primer pairs as referred to by Yi et al. are listed in Table 3 (Yi et al. 2014). All primers used in this study were targeted to the tlh/ldh gene of $V$. parahaemolyticus. The LAMP assay was performed according to the method of Fu et al. (Fu et al. 2016), using Bst WarmStart DNA polymerase (New England Biolabs, Herts, UK; $1 \mu \mathrm{L}$ ) mixed in $22 \mu \mathrm{L}$ buffer solution, which included $0.2 \mu \mathrm{M}$ F3, $0.2 \mu \mathrm{M}$ B3, $1.6 \mu \mathrm{M}$ FIP, $1.6 \mu \mathrm{M}$ BIP, $0.8 \mu \mathrm{M}$ FLP, $0.8 \mu \mathrm{M}$ BIP, $1 \mathrm{M}$ betaine, $8 \mu \mathrm{M} \mathrm{MgSO}_{4}, 1.6$ $\mu \mathrm{M}$ dNTP, $2.5 \mu \mathrm{L} 10 \times$ Thermo pol buffer (New England Biolabs, Herts, UK), $5 \mu \mathrm{M}$ SYTO -9 (Invitrogen, Life Technology, NY, USA), and $\mathrm{ddH}_{2} \mathrm{O}$. Two microliters of DNA template from the enriched culture and fresh MPB was used for each assay, in a total of $25 \mu \mathrm{L}$.

\section{Statistics}

The results were analyzed using one-way analysis of variance (ANOVA) and Dunnett's test using IBM Statistics SPSS v22 (Chicago, IL, USA). $P$ values were twotailed, and the threshold for statistical significance was set at 0.05 . Results are presented as the mean \pm standard error of the mean (SEM) for all independent experiments at each time point. All animal injection experiments were performed in triplicate. Three duplicate test results of each LAMP assay were used only when the triplicate results were consistent.

\section{Results}

Hemolysin detection in V. parahaemolyticus strains

To explore the presence or absence of different hemolysins in $V$. parahaemolyticus strains from various sources, expression of the $t d h$, trh, and $t$ th genes was evaluated to determine $V$. parahaemolyticus hemolysin diversity. Gel electrophoresis results indicated that all 71 strains expressed the th gene, including foodborne, marine, and type strains, apparently, a general hemolysin in $V$. parahaemolyticus. However, only 4 strains possessed the $t d h$

Table 3 LAMP primers used to detect $V$. parahaemolyticus

\begin{tabular}{ll}
\hline Primer number & Sequence $\left(5^{\prime} \rightarrow 3^{\prime}\right)$ \\
\hline F3 & GACAGCTTGTCTGATACAGG \\
B3 & GTTCTTCGCCAGTTTGC \\
FIP & GCGGAAGGTTCTTCGCTTTGGCTGGTTCTTAGGTCACTTC \\
BIP & TCTACAACTGGGCAGTTGGCCTTGATCACCAACCCCTG \\
LoopF & GTCCACACAAAACCGTTGG \\
LoopB & GGCTGGTGAGAACCAATACA \\
\hline
\end{tabular}


gene, all belonging to foodborne $V$. parahaemolyticus isolates. Of the $71 \mathrm{~V}$. parahaemolyticus strains, 5 strains expressed the trh gene, including 4 foodborne isolates and the $V$. parahaemolyticus type strain. The hemolysin features of the strains described above are listed in Table 4.

Based on the presence of the hemolysin regulatory genes, 5 strains were selected for use in animal experiments. $V p 1474$ expressed TDH and TLH encoded by the $t d h$ and $t l h$ genes; $V p 1496$ expressed only TLH encoded by the tlh gene; $V p 1513$ expressed TRH and TLH encoded by the trh and $t$ lh genes. In comparison to the virulence of foodborne $V$. parahaemolyticus strains, Vp $1 \mathrm{~A} 10122$ was chosen as a marine isolate, which expressed only TLH encoded by the $t$ lh gene. $V p$ ATCC 17802 was also chosen as the type strain expressing TRH and TLH encoded by trh and $t$.h.

Identification of $V$. parahaemolyticus colonies on TCBS plates Among localized infection models (Fig. 1a, Table 5), TCBS plates spread with skin samples from mice infected with $V p 1474$ and MPB samples from mice infected with Vp1513 and Vp1A10122 developed scattered V. parahaemolyticus colonies. On TCBS plates spread with skin samples from mice infected with $V p 1496$ and $V p 1513$ and MPB samples from mice infected with Vp1474, Vp1496, and $V p$ ATCC 17802, the presence of $V$. parahaemolyticus was ambiguous due to the presence of other bacteria on the plates. No $V$. parahaemolyticus colonies were observed on plates spread with skin samples from mice infected with $V p$ 1A10122 and $V p$ ATCC 17802.

Among foodborne infection models (Fig. 2a, Fig. S1, and Table 5), TCBS plates spread with stomach tissue samples from mice infected with $V p 1474$ and $V p$ ATCC 17802; small intestine samples from mice infected with all experimental foodborne strains; liver tissue samples from mice infected with $V p 1474$ and $V p 1513$; kidney tissue samples from mice infected with $V p 1474, V p 1513$, $V p 1 \mathrm{~A} 10122$, and $V p$ ATCC 17802; spleen samples from mice infected with $V p 1513$ and $V p$ ATCC 17802; and MPB samples from mice infected with $V p 1496$ showed recognizable $V$. parahaemolyticus colonies. Moreover, on TCBS plates spread with stomach tissue samples from mice infected with $V p 1 \mathrm{~A} 10122$, small intestine samples from mice infected with $V p 1 \mathrm{~A} 10122$, liver tissue samples from mice infected with $V p 1496$ and $V p 1 \mathrm{~A} 10122$, and MPB samples from mice infected with $V p 1513$ and $V p$ ATCC 17802, the presence of $V$. parahaemolyticus was ambiguous as other bacteria competitively grew on the plates. No $V$. parahaemolyticus colony developed on plates spread with stomach tissue samples from mice infected with $V p 1496$ and $V p 1513$; small intestine and liver samples from mice infected with $V p$ ATCC 17802; kidney tissue samples from mice infected with $V p 1496$; spleen samples from mice infected with $V p 1474, V p 1496$, and $V p 1 \mathrm{~A} 10122$; and MPB samples from mice infected with $V p 1474$ and $V p 1 \mathrm{~A} 10122$.

Among wound infection models (Fig. 3a, Fig. S2, and Table 5), TCBS plates spread with stomach, small intestine, liver, kidney, spleen, and MPB samples of mice infected with all experimental foodborne strains and $V p$ ATCC 17802 developed apparent $V$. parahaemolyticus colonies, whereas on TCBS plates spread with stomach, small intestine, liver, kidney, spleen, and MPB samples from mice infected with $V p 1 \mathrm{~A} 10122$, the presence of $V$. parahaemolyticus was ambiguous due to the proliferation of other bacteria on the plates.

In general infection models (Fig. 4a, Fig. S3, and Table 5), TCBS plates spread with stomach samples from mice infected with $V p 1474$; small intestine samples from mice infected with $V p 1474$ and $V p 1496$; liver, kidney, and spleen samples from mice infected with all experimental foodborne strains; and kidney samples from mice infected with Vp ATCC 17802 developed distinct $V$. parahaemolyticus colonies. In addition, TCBS plates spread with small intestine samples from mice infected with $V p 1 \mathrm{~A} 10122$, liver samples from mice infected with $V p$ ATCC 17802, and spleen samples from mice infected with $V p 1 \mathrm{~A} 10122$, the development of $V$. parahaemolyticus was ambiguous as other bacteria competitively proliferated on the plates. No $V$. parahaemolyticus colony developed on the plates spread with stomach samples from mice infected with $V p 1496$, $V p 1513, V p 1 \mathrm{~A} 10122$, and $V p$ ATCC 17802; small intestine samples from mice infected with $V p 1513$ and $V p$ ATCC 17802 ; liver and kidney samples from mice infected with $V p$ 1A10122; and spleen samples from mice infected with Vp ATCC 17802.

Table 4 Hemolysin features of $V$. parahaemolyticus strains

\begin{tabular}{|c|c|}
\hline $\begin{array}{l}\text { Hemolysin gene } \\
\text { expression }\end{array}$ & Strain ID \\
\hline$t d h^{+}, t r h^{-}, t h^{+}$ & Vp 1470, Vp 1474, Vp 1507, Vp 4215 \\
\hline$t d h^{-}, t r h^{+}, t l h^{+}$ & Vp 1511, Vp 1513, Vp 4213, Vp 11577, Vp ATCC 17802 \\
\hline$t d h^{-}, t r h^{-}, t / h^{+}$ & $\begin{array}{l}V p 1463, V p 1464, V p 1465, V p 1466, V p 1467, V p 1468, V p 1469, V p 1471, V p 1472, V p 1473, V p 1475, V p 1476, V p 1477, V p \\
1478, V p 1479, V p 1480, V p 1481, V p 1520, V p 1482, V p 1483, V p 1484, V p 1485, V p 1486, V p 1487, V p 1488, V p 1489, V p 1490, \\
V p 1491, V p 1492, V p 1493, V p 1494, V p 1495, V p 1496, V p 1497, V p 1498, V p 1499, V p 1500, V p 1525, V p 1501, V p 1502, V p \\
1503, V p 1504, V p 1505, V p 1506, V p 1508, V p 1509, V p 1510, V p 1512, V p 1514, V p 1515, V p 1516, V p 1517, V p 1518, V p 1519, \\
V p 1521, V p 1522, V p 1523, V p 1524, V p 1526, V p 1527, V p 1528, V p 1 A 10122\end{array}$ \\
\hline
\end{tabular}




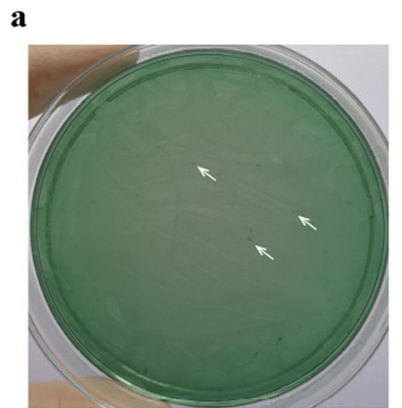

Vp 1474 (skin)

b
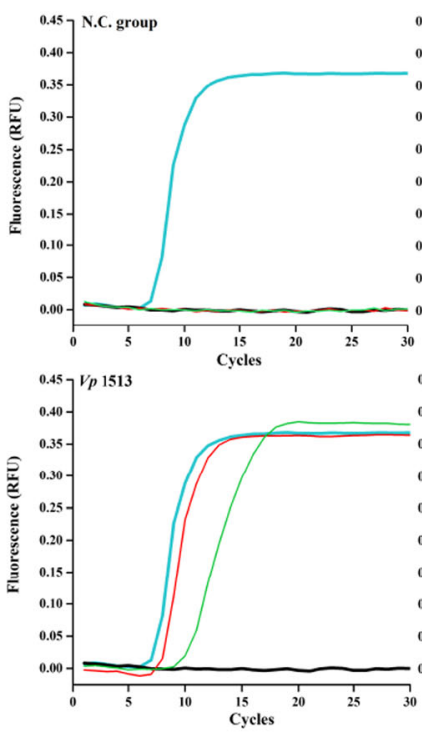

P.C.

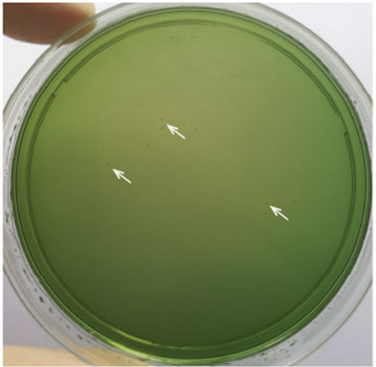

$V p 1513$ (blood)

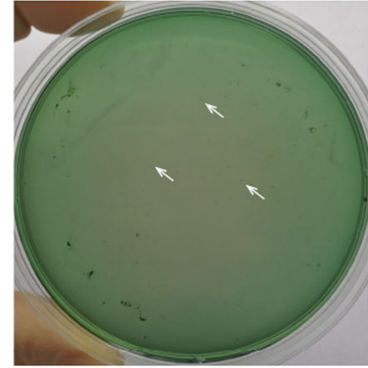

Vp $1 \mathrm{A10122}$ (blood)
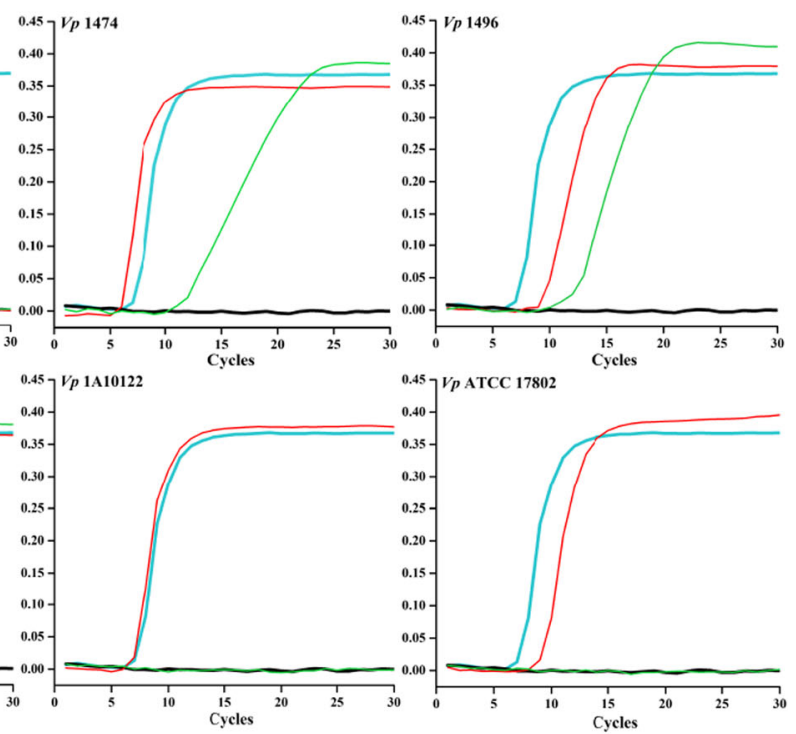

N.C.

Fig. $1 \mathrm{~V}$. parahaemolyticus detection in the localized infection mouse models. a The representative of $V$. parahaemolyticus proliferation identified on the specific TCBS plates from skin and MPB of localized infected mice. $\mathbf{b}$ The representative of $V$. parahaemolyticus detection using rapid LAMP assay from skin and MPB of localized infected mice. White arrowhead, representative sparse colonies of $V$. parahaemolyticus; P.C., positive control using plasmid containing target gene of $\mathrm{V}$. parahaemolyticus as the template of LAMP reaction; N.C., negative control using ddd $\mathrm{H}_{2} \mathrm{O}$ as the template of LAMP reaction; N.C. group, mice injected with PBS as the negative control of localized infection mouse models

MPB samples from mice in the wound infection model were also directly plated for the detection of $V$. parahaemolyticus (Fig. 5a, Table 5). The results indicated that $V$. parahaemolyticus developed on the plates spread with MPB samples from mice infected with $V p 1496, V p 1513$, $V p 1 \mathrm{~A} 10122$, and $V p$ ATCC 17802, while MPB samples from mice infected with $V p 1474$ were interfered by other bacteria.

\section{LAMP detection of $V$. parahaemolyticus}

Results of the LAMP assay demonstrated that after $V$. parahaemolyticus infection of mice through localized inflammation (Fig. 1b, Table 5), the skin from mice infected with all experimental groups, in addition to MPB from mice infected with all experimental foodborne strains, exhibited "S"-shaped curves, confirming the presence of $V$. parahaemolyticus.
LAMP assay results of $V$. parahaemolyticus digestive system infection (Fig. 2b, Table 5) indicated that the stomach of mice infected with $V p 1496, V p 1513$, and $V p$ ATCC 17802 exhibited "S"-shaped curves, as did the small intestine from mice infected with all experimental foodborne strains and $V p 1 \mathrm{~A} 10122$; the liver from mice infected with $V p 1496, V p 1513$, and $V p$ ATCC 17802; the kidney and spleen from mice infected with $V p$ 1513, in addition to the MPB from mice infected with $V p 1496$.

The LAMP assay indicated that, after infection with $V$. parahaemolyticus through wounds (Fig. 3b, Table 5), the MPB from mice infected with all experimental foodborne strains, the marine isolate, and type strain exhibited " $\mathrm{S}$ "-shaped curves. In addition, the stomach, small intestine, liver, kidney, and spleen samples from mice in all experimental groups were positive for $V$. parahaemolyticus. 
Table 5 Results interpretation for $V$. parahaemolyticus infection in target organs of mice

\begin{tabular}{|c|c|c|c|c|c|c|c|c|}
\hline Strain ID & Injection mode & & & & & & & \\
\hline & i.d. & & i.g. & & i.v. & & i.p. & \\
\hline Vp 1474 & $\begin{array}{l}\text { Proliferation } \\
+^{a} \\
+/-^{b} \\
N / A^{c, d}, e, f, g, *\end{array}$ & $\begin{array}{l}\text { LAMP } \\
+^{a, b} \\
N / A^{c, d}, e, f, g,{ }^{*}\end{array}$ & $\begin{array}{l}\text { Proliferation } \\
++^{c, d, e, f} \\
-{ }^{b}, g \\
N / A^{a,}{ }^{*}\end{array}$ & $\begin{array}{l}\text { LAMP } \\
+{ }^{d} \\
-{ }^{\mathrm{b}, c}, \mathrm{e}, \mathrm{f}, \mathrm{g}, * \\
\mathrm{~N} / \mathrm{A}^{\mathrm{a}}\end{array}$ & $\begin{array}{l}\text { Proliferation } \\
+^{b, c, d, e, f, g} \\
+/-^{*} \\
N / A^{a}\end{array}$ & $\begin{array}{l}\text { LAMP } \\
+^{b, c, d, e, f, g, *} \\
N / A^{a}\end{array}$ & $\begin{array}{l}\text { Proliferation } \\
+^{c, d, e, f, g} \\
N / A^{a, b},{ }^{*}\end{array}$ & $\begin{array}{l}\text { LAMP } \\
+^{c, d, e, f, g} \\
N / A^{a, b}{ }^{*}\end{array}$ \\
\hline Vp 1496 & $\begin{array}{l}+/-^{a, b} \\
N / A^{c, d}, e, f, g, *\end{array}$ & $\begin{array}{l}+^{a, b} \\
N / A^{c, d}, e, f, g, *\end{array}$ & $\begin{array}{l}+^{b, d} \\
+/-^{e} \\
-_{c, f, g}, g \\
N / A^{a, *}\end{array}$ & $\begin{array}{l}+^{b, c, d, e, *} \\
-^{f, g} \\
N / A^{a}\end{array}$ & $\begin{array}{l}+^{b, c, d}, e, f, g,{ }^{*} \\
N / A^{a}\end{array}$ & $\begin{array}{l}+^{b, c}, d, e, f, g,{ }^{*} \\
N / A^{a}\end{array}$ & $\begin{array}{l}+^{d, e, f, g} \\
-{ }^{c} \\
N / A^{a, b,{ }^{*}}\end{array}$ & $\begin{array}{l}+^{c, d, e, f, g} \\
N / A^{a, b}, *\end{array}$ \\
\hline Vp 1513 & $\begin{array}{l}+^{b} \\
+/-^{a} \\
N / A^{c, d}, e, f, g, *\end{array}$ & $\begin{array}{l}+^{a, b} \\
N / A^{c, d}, e, f, g, *\end{array}$ & $\begin{array}{l}+{ }^{\mathrm{d}, \mathrm{e}, \mathrm{f}, \mathrm{g}} \\
+/-^{\mathrm{b}} \\
-^{\mathrm{c}} \\
\mathrm{N} / \mathrm{A}^{\mathrm{a}, *}\end{array}$ & $\begin{array}{l}+{ }^{c, d, e, f, g} \\
-^{b, *} \\
N / A^{a}\end{array}$ & $\begin{array}{l}+^{b, c, d}, e, f, g, * \\
N / A^{a}\end{array}$ & $\begin{array}{l}+^{b, c}, d, e, f, g,{ }^{*} \\
N / A^{a}\end{array}$ & $\begin{array}{l}+^{e, f, g} \\
-^{c, d} \\
N / A^{a, b}, *\end{array}$ & $\begin{array}{l}+^{c, d, e, f, g} \\
N / A^{a, b, *}\end{array}$ \\
\hline Vp 1A10122 & $\begin{array}{l}+^{b} \\
-{ }^{a} \\
N / A^{c, d}, e, f, g,{ }^{*}\end{array}$ & 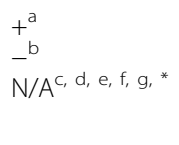 & $\begin{array}{l}+^{f} \\
+/-^{c, d}, \mathrm{~d} \\
-^{\mathrm{b}, \mathrm{g}} \\
\mathrm{N} / \mathrm{A}^{\mathrm{a}, *}\end{array}$ & $\begin{array}{l}+^{d} \\
-b, c, e, f, g, * \\
N / A^{a}\end{array}$ & $\begin{array}{l}+^{*} \\
+/-^{b}, c, d, e, f, g \\
N / A^{a}\end{array}$ & $\begin{array}{l}+^{b, c}, d, e, f, g{ }^{*} \\
N / A^{a}\end{array}$ & $\begin{array}{l}+/{ }^{d, g} \\
-^{c, e, f} \\
N / A^{a, b,}{ }^{*}\end{array}$ & $\begin{array}{l}+^{\mathrm{d}, \mathrm{g}} \\
{ }^{\mathrm{c}, \mathrm{e}, \mathrm{f}} \\
\mathrm{N} / \mathrm{A}^{\mathrm{a}, \mathrm{b}_{,}}\end{array}$ \\
\hline Vp ATCC 17802 & $\begin{array}{l}+/^{b} \\
-^{a} \\
N / A^{c, d}, e, f, g,{ }^{*}\end{array}$ & 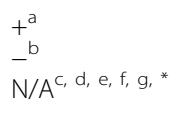 & $\begin{array}{l}+^{c, f, g} \\
+/-^{b} \\
-{ }^{d, e} \\
N^{\prime} / A^{a^{*}}{ }^{*}\end{array}$ & $\begin{array}{l}+{ }^{c, e} \\
-b, d, f, g, * \\
N / A^{a}\end{array}$ & $\begin{array}{l}+^{b, c, d}, e, f, g,{ }^{*} \\
N / A^{a}\end{array}$ & $\begin{array}{l}+_{-}^{b, c, d}, e, f, g \\
-{ }^{*} / A^{a}\end{array}$ & $\begin{array}{l}+^{f} \\
+/-^{e} \\
-^{c, d}, g \\
N / A^{a, b, *}\end{array}$ & $\begin{array}{l}+^{\mathrm{d}, \mathrm{g}} \\
{ }^{\mathrm{c}, \mathrm{e}, \mathrm{f}} \\
\mathrm{N}^{\mathrm{N}} \mathrm{A}^{\mathrm{a}, \mathrm{b},{ }^{*}}\end{array}$ \\
\hline
\end{tabular}

N/A not applicable

${ }^{a}$ Local skin; ${ }^{b}$ MPB; ${ }^{c}$ stomach; ${ }^{d}$ small intestine; ${ }^{\mathrm{e}}$ liver; ${ }^{\mathrm{f}}$ kidney; ${ }^{\mathrm{g}}$ spleen; ${ }^{*}$ directly detection from MPB without proliferation; +, V. parahaemolyticus proliferation observed on the plate or LAMP positive; $+/-$, bacteria unidentified proliferation observed on the plate; - , no bacteria proliferation observed on the plate or LAMP negative

The LAMP assay indicated that the major organs from mice infected with all experimental foodborne strains exhibited "S"-shaped curves when mice were infected with $V$. parahaemolyticus through general infection (Fig. 4b, Table 5), while the small intestine and spleen were the most sensitive target organs in mice infected with the marine strain $V p$ 1A10122 or type strain Vp ATCC 17802.

The LAMP assay also demonstrated that $V p 1496$ could be successfully identified even in fresh MPB without proliferation from mice in the foodborne infection model (Fig. 5b, Table 5). When mice were infected with $V$. parahaemolyticus in the wound model, the LAMP assay successfully detected most experimental strains, including Vp1474, Vp1496, Vp1513, and Vp1A10122.

\section{Discussion}

Seafoods contaminated with $V$. parahaemolyticus, a species of seafood-derived Vibrio, are common in coastal cities. Combined with the high rates of exposure to marine or brackish environments, the abundance of $V$. parahaemolyticus results in many aquatic-derived human infections. Because its symptoms of infection are similar to those of other bacteria, such as Escherichia coli and Salmonella spp. (Park et al. 2018), little attention is generally paid to $V$. parahaemolyticus. Therefore, studies on the epidemiology of $V$. parahaemolyticus are limited, although there are considerably greater numbers of vulnerable populations than reported internationally.
Before the 1960s, V. parahaemolyticus outbreaks were limited to Japan (Fujino et al. 1953), but the very first large outbreak of $V$. parahaemolyticus was reported in Maryland, USA early in 1971, due to the ingestion of contaminated crab meat (Center for Food Safety and Applied Nutrition (CFSAN) 2000). From then on, $V$. parahaemolyticus infection has become a global problem according to data from the Center for Disease Control and Prevention (CDC) (CDC 1998), including areas around the Pacific, Atlantic, and Indian oceans.

\section{Virulence specificity vs. $V$. parahaemolyticus infection}

When $V$. parahaemolyticus invades a host, multiple toxins are released, and these accelerate deterioration of the site of infection. TDH, TRH, and TLH are the three major toxins produced during $V$. parahaemolyticus proliferation (DePaola et al. 2003). Among these, TDH and TRH are reported to be the two main pathogenic factors (Honda et al. 1988; Nishibuchi and Kaper 1995).

TDH is the primary toxin produced by $V$. parahaemolyticus and is responsible for damage to erythrocytes and it also exhibits multi-cell type cytotoxicity. Sequence variations of the $t d h$ gene that encodes for TDH exist in $V$. parahaemolyticus strains. The $t d h$ gene family has formed as a result of phylogenetic evolution and gene mutation (Tsunasawa et al. 1987). TRH was purified and characterized in 1988 as a $V$. parahaemolyticus hemolysin related to TDH by Honda et al. (Honda et al. 1988) also identified in 1989 by Nishibuchi et al. (Nishibuchi 


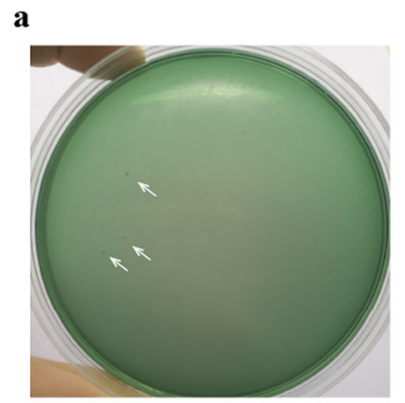

$V p 1474$ (stomach)

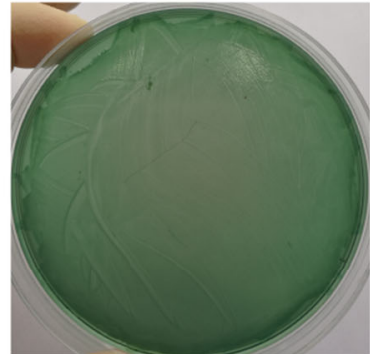

$V p 1513$ (liver)

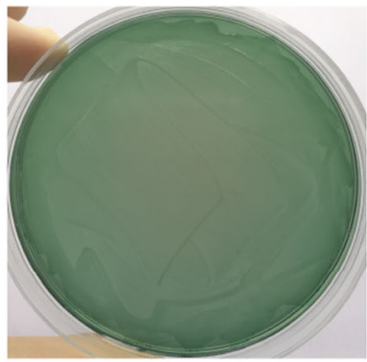

$V p 1496$ (small intestine)

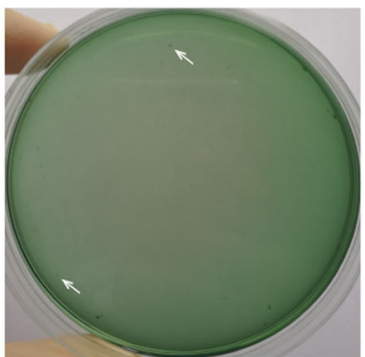

Vp 1A10122 (kidney)

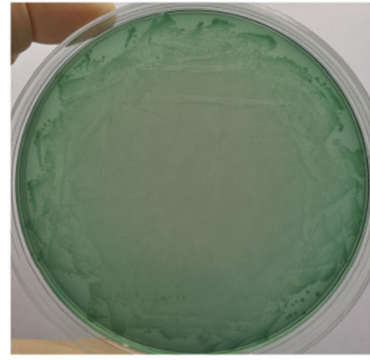

$V p 1496$ (blood)

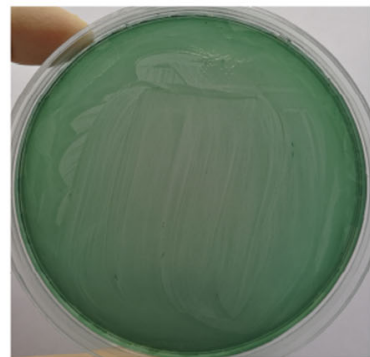

$V p$ ATCC 17802 (spleen)

b
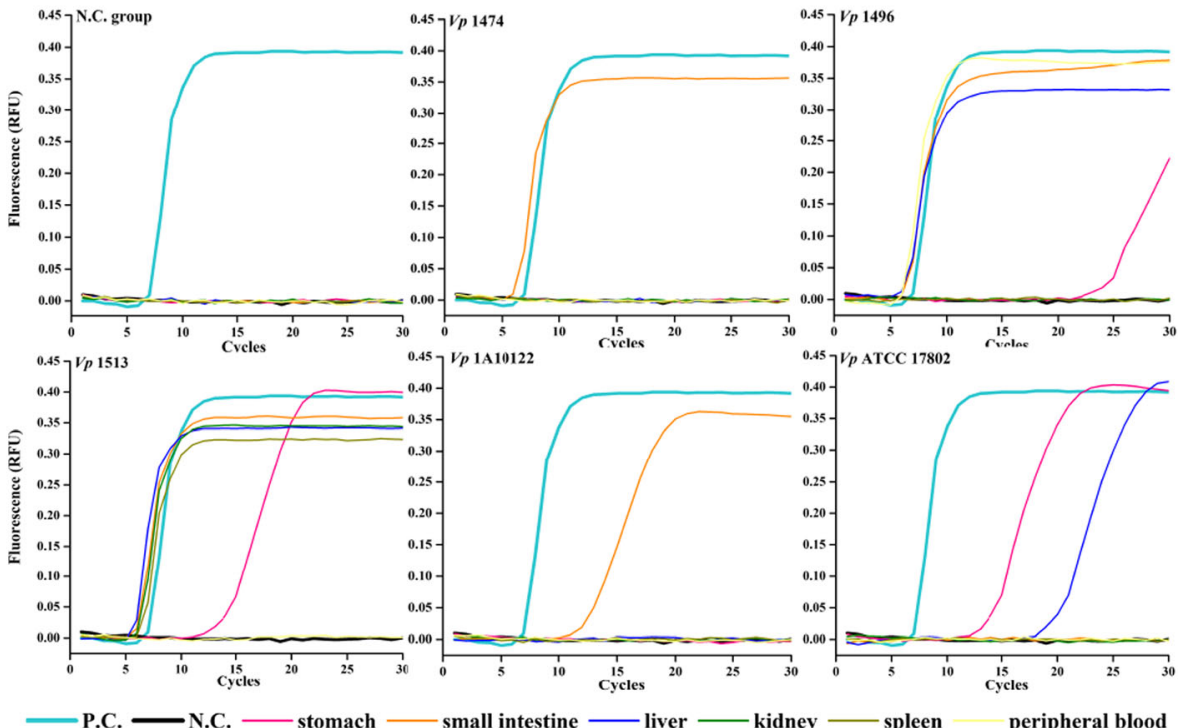

spleen

peripheral blood

Fig. $2 \mathrm{~V}$. parahaemolyticus detection in the foodborne infection mouse models. a The representative of $V$. parahaemolyticus proliferation identified on the specific TCBS plates from the stomach, small intestine, liver, kidney, spleen, and MPB of foodborne infected mice. $\mathbf{b}$ The representative of $V$. parahaemolyticus detection using rapid LAMP assay from the stomach, small intestine, liver, kidney, spleen, and MPB of foodborne-infected mice. White arrowhead, representative sparse colonies of $V$. parahaemolyticus; P.C., positive control using plasmid-containing target gene of $V$. parahaemolyticus as the template of LAMP reaction; N.C., negative control using $\mathrm{dd}_{2} \mathrm{O}$ as the template of LAMP reaction; N.C. group, mice injected with PBS as the negative control of foodborne infection mouse models

et al. 1989). TRH is another important hemolysin and is a recognized virulence factor. It is encoded by the trh gene, which is closely related to the $t d h$ gene, having up to $68 \%$ sequence homology (Bej et al. 1999). Therefore, TRH has the same intestinal toxicity but a different hemocytocatheresis as TDH (Park et al. 2004), also often detected in clinical strains of $V$. parahaemolyticus.
TLH is a separate virulence protein and encoded by the $t$ th gene. It does not produce hemolysis on Wagatsuma agar and is not responsible for human infection by $V$. parahaemolyticus $t d h^{+}$or $t r h^{+}$isolates (McCarthy et al. 1999). Different from the $t d h$ and $t r h$ gene families, $t$ th is a single gene and exists in all subtypes of $V$. parahaemolyticus including clinical and environmental 
$\mathbf{a}$

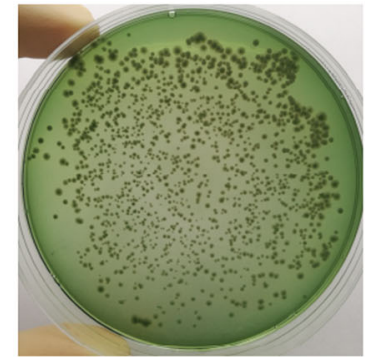

Vp 1474 (stomach)

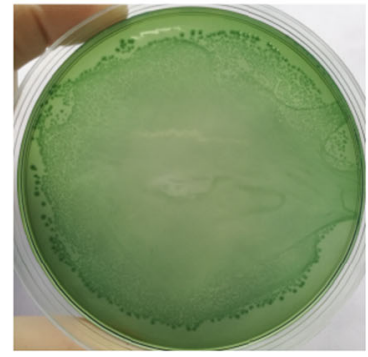

Vp 1513 (kidney)

b
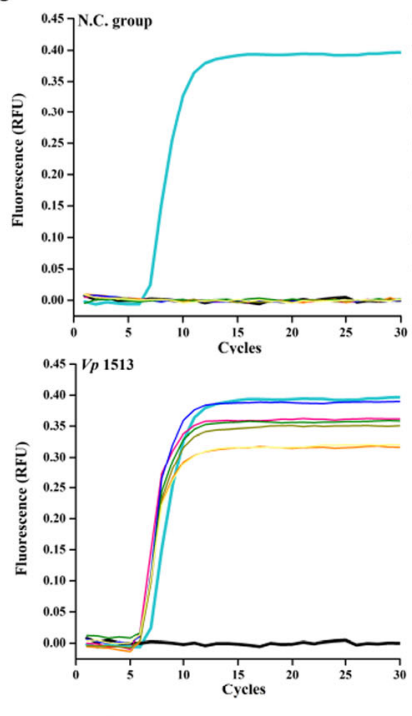

b

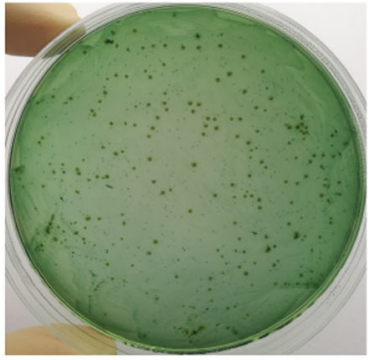

Vp 1474 (liver)

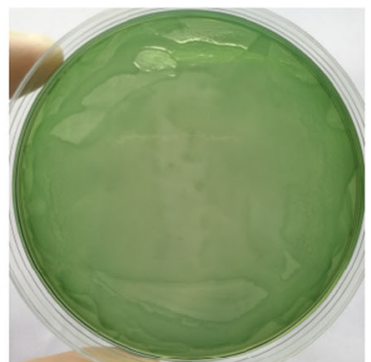

Vp 1513 (spleen)

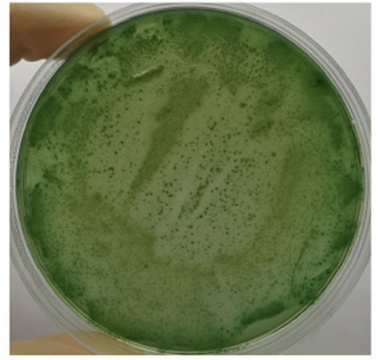

$V p 1496$ (small intestine)

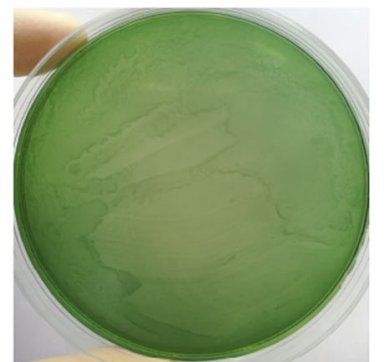

Vp ATCC 17802 (blood)

$\longrightarrow$ P.C. - N.C. - stomach
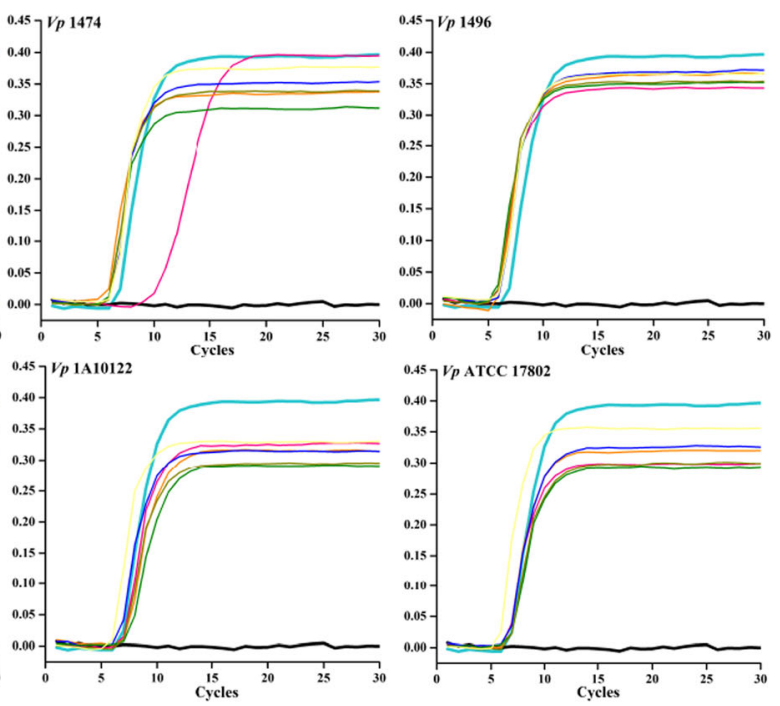

Fig. $3 \mathrm{~V}$. parahaemolyticus detection in the wound infection mouse models. a The representative of $\mathrm{V}$. parahaemolyticus proliferation identified on the specific TCBS plates from the stomach, small intestine, liver, kidney, spleen, and MPB of wound-infected mice; $\mathbf{b}$ The representative of $V$. parahaemolyticus detection using rapid LAMP assay from the stomach, small intestine, liver, kidney, spleen, and MPB of wound-infected mice. P.C., positive control using plasmid-containing target gene of $V$. parahaemolyticus as the template of LAMP reaction; N.C., negative control using $\mathrm{ddH}_{2} \mathrm{O}$ as the template of LAMP reaction; N.C. group, mice injected with PBS as the negative control of wound infection mouse models

isolates (Taniguchi et al. 1990). Therefore, TLH is a $V$. parahaemolyticus-specific virulence factor (Taniguchi et al. 1985; Taniguchi et al. 1990). However, the mechanism of action of TLH remains unclear.

Although TDH and TRH are the two major virulence factors of $V$. parahaemolyticus, the Kanagawa reaction is not necessarily linked to these two factors (Tada et al. 1992). Bej et al. confirmed that $t d h^{-}$and $t r h^{-} V$. parahaemolyticus still cause a positive Kanagawa reaction. Therefore, the clinical result of that specific assay (Kanagawa) is not $100 \%$ correct for the identification of $V$. parahaemolyticus (Ottaviani et al. 2012). Thus, in our study, we detected expression of all 3 types of hemolysin produced by $V$. parahaemolyticus. The hemolysin assay indicated that all $71 \mathrm{~V}$. parahaemolyticus strains produced TLH, consistent with previous studies. Of these 
a

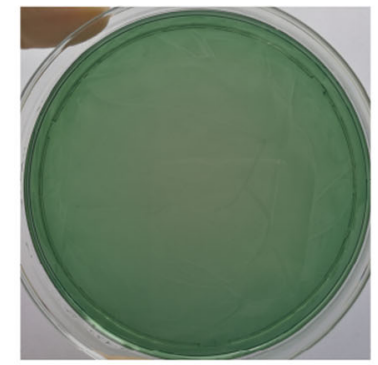

Vp 1474 (stomach)

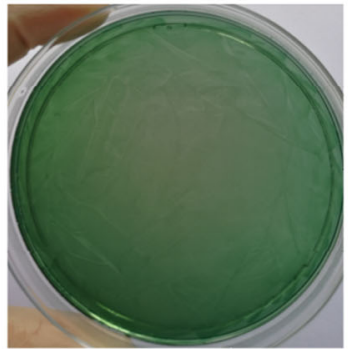

Vp 1513 (liver)

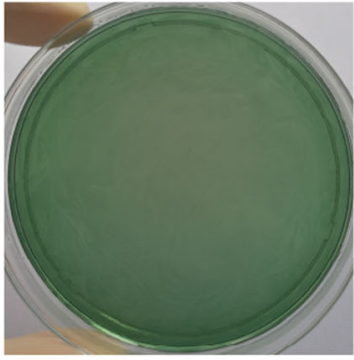

Vp 1474 (spleen)

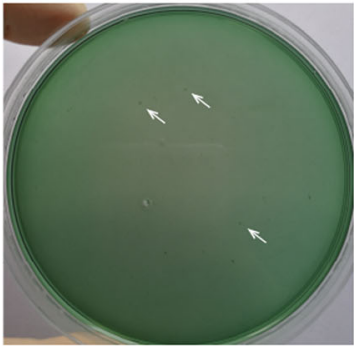

Vp АТCC 17802 (kidney)

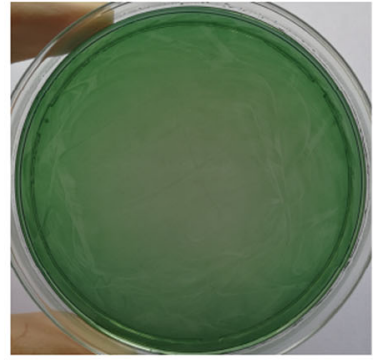

Vp 1496 (small intestine)

b
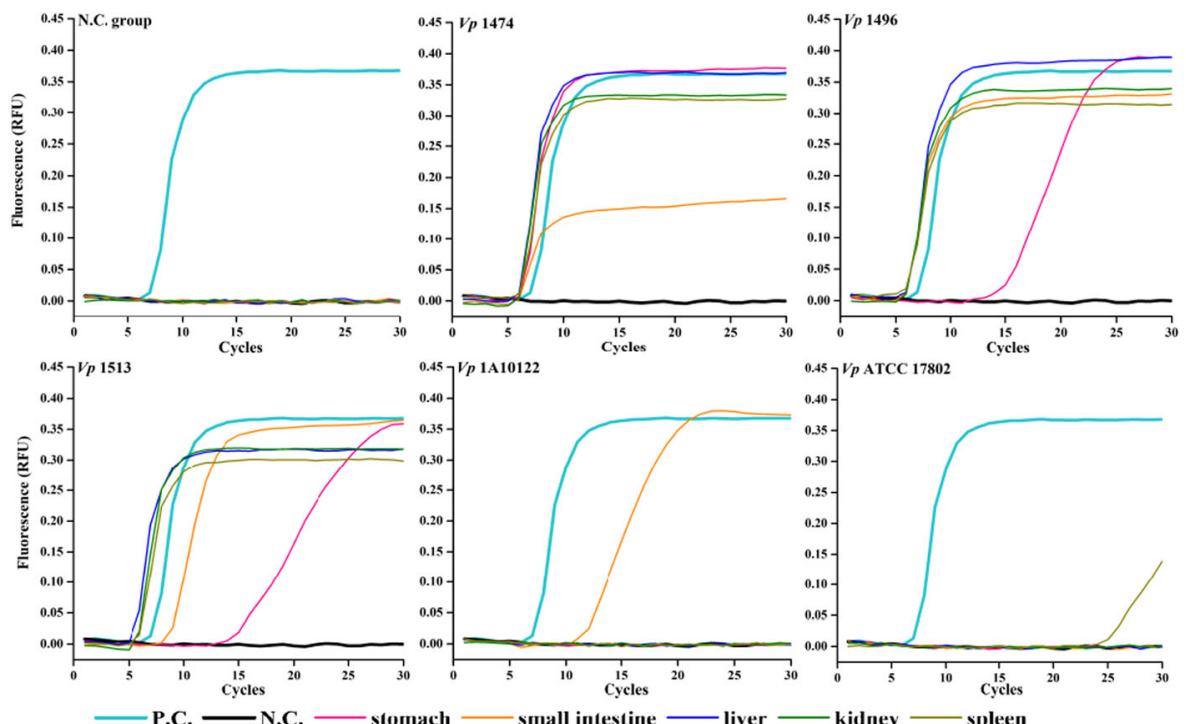

Fig. $4 \mathrm{~V}$. parahaemolyticus detection in the general infection mouse models. a The representative of $V$. parahaemolyticus proliferation identified on the specific TCBS plates from the stomach, small intestine, liver, kidney, and spleen of general infected mice; $\mathbf{b}$ The representative of $V$. parahaemolyticus detection using rapid LAMP assay from the stomach, small intestine, liver, kidney, and spleen of general infected mice. White arrowhead, representative sparse colonies of $V$. parahaemolyticus; P.C., positive control using plasmid-containing target gene of $V$.

parahaemolyticus as the template of LAMP reaction; N.C., negative control using $\mathrm{ddH}_{2} \mathrm{O}$ as the template of LAMP reaction; N.C. group, mice injected with PBS as the negative control of general infection mouse models

strains, 3 foodborne $V$. parahaemolyticus isolates had genes for the expression of TDH, TRH, and TLH. To ensure all $V$. parahaemolyticus subtypes from different sources were included in the animal experiments, 5 strains (considering both the source and virulence factors) were chosen to comprehensively represent $V$. parahaemolyticus lineages.
In previous studies, Tsai et al. suggested that there were fewer than $5 \%$ prevalent $V$. parahaemolyticus strains in environmental or marine food isolates (Tsai et al. 2013), and so, it was hypothesized that the pathogenicity of $V$. parahaemolyticus environmental isolates was weaker than clinical isolates. However, the continuously increasing proportion of pathogenic $V$. parahaemolyticus has drawn 
a

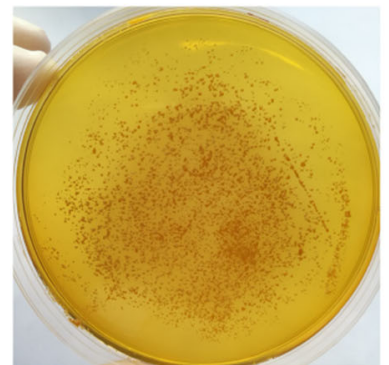

Vp 1474 (blood)

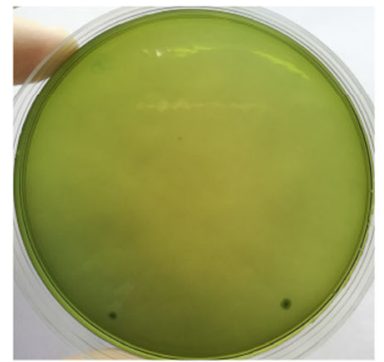

Vp $1 \mathrm{A10122}$ (blood)

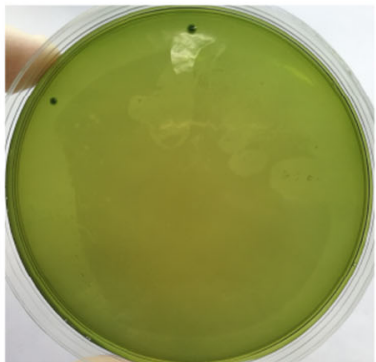

Vp 1496 (blood)

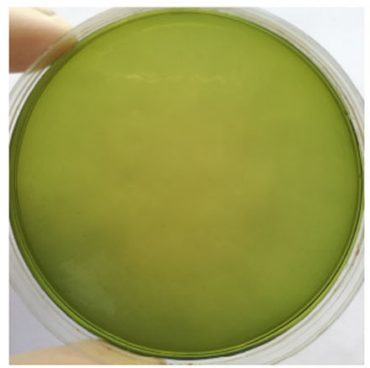

Vp ATCC17802 (blood)

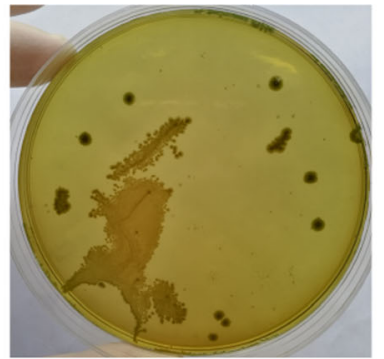

Vp 1513 (blood)

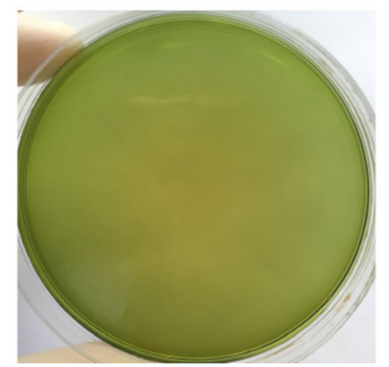

N.C. group (blood)

b

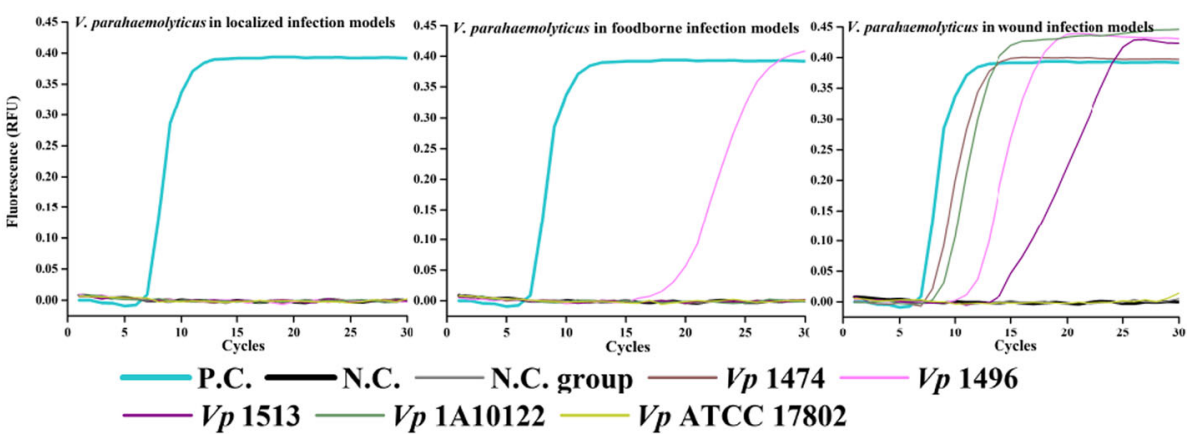

Fig. $5 \mathrm{~V}$. parahaemolyticus direct detection from fresh MPB of infected mice via different infection routes. a The representative of $V$. parahaemolyticus proliferation identified on the specific TCBS plates from fresh MPB of wound-infected mice; $\mathbf{b}$ The representative of $V$. parahaemolyticus detection using rapid LAMP assay from fresh MPB of localized, foodborne-derived, and wound infection mice. P.C., positive control using plasmid containing target gene of $\mathrm{V}$. parahaemolyticus as the template of LAMP reaction; N.C., negative control using ddH ${ }_{2} \mathrm{O}$ as the template of LAMP reaction; N.C. group, mice injected with PBS as the negative control of general infection mouse models

attention to food safety. Up to the year 2000, a maximum of $6 \%$ of $V$. parahaemolyticus environmental isolates were reported to express $t d h / t r h$ in Europe and Asia (Letchumanan et al. 2014), leaping to more than $8 \%\left(t d h^{+}\right)$and $12 \%\left(t^{+} h^{+}\right.$(Yang et al. 2017b). In the present study, we coincidently found that $5.88 \%$ and $7.04 \%$ of our tested $V$. parahaemolyticus strains expressed $t d h / t r h$ genes. In the future, this significantly increasing trend is very likely to be a factor influencing the outbreak of human infections caused by $V$. parahaemolyticus.

\section{Source specificity vs. $V$. parahaemolyticus infection}

Apart from virulence gene expression, there is a close relationship between the source of a Vibrio isolate and the severity of any resulting infection. Baker-Austin et al. reviewed the differences in dissemination pathways and infection gradients due to Vibrio source diversity (BakerAustin et al. 2018), which also have different infection risks. The most important source of $V$. parahaemolyticus in human infection is marine food products (Zhang et al. 2017). V. parahaemolyticus is a pathogen that exists in multiple water sources. Despite its lack of pathogenicity in fresh water, several studies have confirmed human infection by $V$. parahaemolyticus isolated from sea water. Another infection route that is easily ignored is the cross contamination of cooked foods transferred to humans through food or wounds (Brennan-Krohn et al. 2016).

The correlation between the source of Vibrio and type of infection may be reflected in genotype (Jones and 
Oliver 2009), which has previously been reported by Rosche et al. for $V$. vulnificus (Rosche et al. 2005). In addition, their infection data concluded that $90 \%$ of $\mathrm{C}$ genotype $V$. vulnificus strains was clinical isolates while 85 90\% of E-genotype strains were environmental isolates (Rosche et al. 2005). This data on strain heterogeneity has reinforced the correlation between Vibrio genotype and pathogenicity. The information described above raises a warning for the optimization of Vibrio source identification and the updating of related data. The Vibrio source can be confirmed by whole genome sequencing (Orata et al. 2014), therefore an understanding of the Vibrio source may provide an accurate reference to answer future research questions.

For $V$. parahaemolyticus, different sources typical of specific serotypes can lead to particular outbreaks of human infections. The $V$. parahaemolyticus strains responsible for the majority of outbreaks in the USA have different serotypes from those responsible for outbreaks in Japan. Although a V. parahaemolyticus outbreak usually happens within a limited region caused by strains with similar genotypes, a close relationship between strain heterogeneity and pathogenicity remains (BakerAustin et al. 2018), e.g., the pandemic O3:K6 V. parahaemolyticus strain is generally present in the Bay of Bangladesh region (Nair et al. 2007). However, the mechanism by which a bacterial strain source affects a Vibrio outbreak is still not well understood.

Comparative research on pathogenic V. parahaemolyticus strains has shown that there is a diversity of pathogenicity when clinical $V$. parahaemolyticus are isolated from different areas of water. Considering both foodborne infections and regional proliferation of $V$. parahaemolyticus, the $V$. parahaemolyticus strains were from both foodborne and seawater isolates, with ATCC type strain as the standard for the experiments. Foodborne $V$. parahaemolyticus strains were all isolated from domestic consumption of seafood, including seashells, crabs, and oysters, and the seawater strain was isolated from the south China sea. The results obtained in our study mirror the $V$. parahaemolyticus infections seen in China and our LAMP assay provides a possible solution for the rapid detection of $V$. parahaemolyticus in current circumstances.

\section{LAMP detection sensitivity}

Based on Nucleic acid-PCR technology, the greatest advantage of the LAMP assay lies in its high sensitivity and rapid speed of amplification. With specific pairs of primers, the LAMP assay minimized the template to 2 CFUs at most during its reaction, while other PCR methods require $10 \sim 10^{3}$-fold additional templates compared with the LAMP assay (Law et al. 2015). Other than these advantages, the LAMP assay is simple to operate and is of low cost. Thus, the LAMP assay has fewer disadvantages than other methods.

Among the different routes of infection, $V$. parahaemolyticus wound infections were the most easily detected by the LAMP assay. Wound infections caused by $V$. parahaemolyticus are not common, but they are serious. Although there are few such reports, it can be lifethreatening. In this study, we demonstrated that early stages of $V$. parahaemolyticus infection can easily be detected using a LAMP assay with visual interpretation of the results.

Data using the LAMP assay to detect $V$. parahaemolyticus strains in various organs indicated that foodborne strains were most sensitive to the assay, and $V$. parahaemolyticus was detected in all organs tested in localized, wound, and general infection models. Although $V$. parahaemolyticus could not be detected in all mice in the foodborne infection model, bacteria that spread to the small intestine could be detected. Our results indicated that the small intestine was a good target organ to detect foodborne $V$. parahaemolyticus infection. On the other hand, combined with different virulence values for each isolate, infectivity varied. In the foodborne infection model, the stomach was the first organ to encounter $V$. parahaemolyticus. The LAMP assay, on the contrary showed false positive results. In all tested groups, $V p$ 1513 was detected with the highest efficiency, thereby demonstrating its high-level infectivity. In combination with the results of virulence gene expression, our findings demonstrated that the LAMP assay responded differently to various $V$. parahaemolyticus strains.

When using the LAMP assay to detect $V$. parahaemolyticus in different organs, the sensitivity of the LAMP assay varied in the different infection models. The results implied that the infection route affected how $V$. parahaemolyticus invaded the host, and this confirms the concern and suggestion of Baker-Austin et al., who highlighted in their research the importance of epidemiology data updates, such as source of Vibrio and route of transmission (Baker-Austin et al. 2018). Combined with the LAMP results of different routes to infection, our results offer a personalized method for tracing back to the original explanation for human infection by $V$. parahaemolyticus.

\section{Conclusions and future perspectives}

Based on previous reports, only a limited number of $V$. parahaemolyticus infection cases resulted in death. Despite this, V. parahaemolyticus can still cause human infections in a wide range of populations. The increasing antibiotic resistance of pathogenic bacteria has encouraged the marine culture industry to raise the concentrations of antibiotics added to sea water (Letchumanan et al. 2014), causing inevitable antibiotic tolerance in $V$. parahaemolyticus, especially to carbapenems resistance 
(Lee et al. 2018). This situation indirectly leads to the excessive proliferation of $V$. parahaemolyticus. Therefore, conducting early screening of potential susceptible populations plays a role in pre-warning for the limited prevention measure of its infection.

Therefore, in the early stages of $V$. parahaemolyticus infection, non-invasive and rapid detection of the bacteria is essential to prevent it from spreading further. Under this circumstance, our LAMP results demonstrated a possible method to directly detect $V$. parahaemolyticus in peripheral blood (PB). In this study, although the results showed different sensitivity when the LAMP assay was applied to specific infection models, the assay still has potential. When using the LAMP assay in the general infection model, positive results were obtained from all target organs, indicating that the LAMP assay could be used for $V$. parahaemolyticus screening.

Thus, the LAMP assay makes it possible to directly detect $V$. parahaemolyticus without the need for ex vivo studies. Although there are some drawbacks to the application of this method, the rapid detection speed, intuitive results, and high efficiency are promising for further investigation for use in clinical cases. In addition, optimization of the LAMP assay requires further improvement.

\section{Supplementary information}

Supplementary information accompanies this paper at https://doi.org/10. 1186/s13213-020-01585-6.

Additional file 1: Fig. S1. V. parahaemolyticus identification on TCBS plates in the foodborne infection mouse models. The representative of $V$. parahaemolyticus development on the specific TCBS plates from stomach, small intestine, liver, kidney and spleen of foodborne infected mice; white arrowhead, representative sparse colonies of $V$. parahaemolyticus.

Additional file 2: Fig. S2. $V$. parahaemolyticus identification on TCBS plates in the wound infection mouse models. The representative of $V$. parahaemolyticus development on the specific TCBS plates from stomach, small intestine, liver, kidney, spleen and MPB of wound infected mice.

Additional file 3: Fig. S3. V. parahaemolyticus identification on TCBS plates in the general infection mouse models. The representative of $V$. parahaemolyticus development on the specific TCBS plates from small intestine, liver, kidney and spleen of general infected mice.

\section{Abbreviations \\ $\mathrm{G}^{-}$: Gram-negative; NFDOSS: National Foodborne Disease Outbreaks Surveillance System; NASBA: Nuclear acid sequence-based amplification; FISH: Fluorescence in situ hybridization; LAMP: Loop-mediated isothermal amplification; TCBS: Thiosulfate citrate bile salts sucrose; SPF: Specific- pathogen-free; i.d.: Intradermal injection; i.g.: Intragastric gavage; i.v.: Intravenous injection; i.p.: Intraperitoneal injection; MPB: Mouse peripheral blood; ACD: Acid citrate-dextrose; ANOVA: One-way analysis of variance; SEM: Standard error of the mean; CDC: Center for Disease Control and Prevention; PB: Peripheral blood}

\section{Acknowledgements}

We thank Dr. Shenghui Cui for the generous gift of $V$. parahaemolyticus foodborne strains and for the help in their preparation. We thank Dr. Lei Shi for generously providing us with the procedure of LAMP method and the guidance.

\section{Authors' contributions}

SZ and LjZ conceived this study; KfF and LjZ designed the research; JL, JfL and KWQ performed the experiments; JfL and CIW analyzed experimental data; JL, JfL, KfF, and XjY wrote the paper. JL and JfL contributed equally to this work. All authors discussed the results, agreed on the interpretation and contributed in the finalization of the manuscript.

\section{Funding}

This work was funded by the Medical and health key project (grant no. 14J004, 12J025), the Medical Innovation Research Program (grant no. CX19027), and the Innovation Incubation Fund of the Navy General Hospital (grant no. CXPY201822).

\section{Availability of data and materials}

All data generated or analyzed during this study are included in this published article.

\section{Ethics approval and consent to participate}

All applicable international, national, and/or institutional guidelines for the care and use of animals were followed. All animal procedures complied with the institutional and national guidelines prescribed by the International Council for Laboratory Animal Science (ICLAS) from the Ministry of Health of the People's Republic of China. All procedures performed in studies involving animals were in accordance with the ethical standards of Animal Ethics Committee of Navy General Hospital of Chinese PLA at which the studies were conducted.

\section{Consent for publication}

$\mathrm{N} / \mathrm{A}$.

\section{Competing interests}

The authors declare that they have no competing interests.

Received: 14 July 2019 Accepted: 21 February 2020

Published online: 24 June 2020

\section{References}

Alam MJ, Tomochika KI, Miyoshi SI, Shinoda S (2002) Environmental investigation of potentially pathogenic Vibrio parahaemolyticus in the Seto-Inland Sea, Japan. FEMS microbiology letters 208:83-87. https://doi.org/10.1111/j.15746968.2002.tb11064.x

Baker-Austin C, Oliver JD, Alam M, Ali A, Waldor MK, Qadri F, Martinez-Urtaza J (2018) Vibrio spp. infections. Nature reviews Disease primers 4:8. https://doi. org/10.1038/s41572-018-0005-8

Barker WHJ (1974) In: Fujino T, Sakaguchi G, Sakazaki R, Takeda Y (eds) International Symposium on Vibrio parahaemolyticus. Saikon Publishing Co., Ltd., Tokyo, pp 47-52

Bej AK, Patterson DP, Brasher CW, Vickery MC, Jones DD, Kaysner CA (1999) Detection of total and hemolysin-producing Vibrio parahaemolyticus in shellfish using multiplex PCR amplification of $t / h$, $t d h$ and trh. Journal of microbiological methods 36:215-225

Brennan-Krohn T, Pica N, Sandora TJ, McAdam A (2016) Closing the brief case: safe to go back in the water? Vibrio parahaemolyticus wound infection associated with brackish water. Journal of clinical microbiology 54:1672. https://doi.org/10.1128/jcm.02661-15

CDC (1998) Outbreak of Vibrio parahaemolyticus infections associated with eating raw oysters--Pacific Northwest, 1997. MMWR Morb Mortal Wkly Rep 47:457462

Center for Food Safety and Applied Nutrition (CFSAN) (2000) Draft risk assessment on the public health impact of Vibrio parahaemolyticus in raw molluscan shellfish. U. S. Food \& Drug Administration. Washington, DC.

Chen S, Ge B (2010) Development of a toxR-based loop-mediated isothermal amplification assay for detecting Vibrio parahaemolyticus. BMC microbiology 10:41. https://doi.org/10.1186/1471-2180-10-41

Cho $Y$ et al (2017) Rapid identification of Vibrio species isolated from the southern coastal regions of Korea by MALDI-TOF mass spectrometry and comparison of MALDI sample preparation methods. J Microbiol Biotechnol 27:1593-1601. https://doi.org/10.4014/jmb.1704.04056

Croci $L$ et al (2007) Comparison of different biochemical and molecular methods for the identification of Vibrio parahaemolyticus. Journal of applied microbiology 102:229-237. https://doi.org/10.1111/j.1365-2672.2006.03046.x 
Dea-Ayuela MA, Galiana-Rosello C, Lalatsa A, Serrano DR (2018) Applying loopmediated isothermal amplification (LAMP) in the diagnosis of malaria, leishmaniasis and trypanosomiasis as point-of-care tests (POCTs). Curr Top Med Chem 18:1358-1374. https://doi.org/10.2174/ 1568026618666181025095735

DePaola A, Hopkins LH, Peeler JT, Wentz B, McPhearson RM (1990) Incidence of Vibrio parahaemolyticus in U.S. coastal waters and oysters. Applied and environmental microbiology 56:2299-2302

DePaola A et al (2003) Molecular, serological, and virulence characteristics of Vibrio parahaemolyticus isolated from environmental, food, and clinical sources in North America and Asia. Applied and environmental microbiology 69:3999-4005

Di Pinto A, Terio V, Di Pinto P, Colao V, Tantillo G (2012) Detection of Vibrio parahaemolyticus in shellfish using polymerase chain reaction-enzyme-linked immunosorbent assay. Lett Appl Microbiol 54:494-498. https://doi.org/10. 1111/j.1472-765X.2012.03231.X

Fu K, Li J, Wang Y, Liu J, Yan H, Shi L, Zhou L (2016) An innovative method for rapid identification and detection of Vibrio alginolyticus in different infection models. Frontiers in microbiology 7:651. https://doi.org/10.3389/fmicb.2016.00651

Fujino T, Okuno Y, Nakada D, Aoyama A, Fukai K, Mukai T, Ueho T (1953) On the bacteriological examination of Shirasu food poisoning vol:4

Fujita N, Ayukawa Y, Fuke M, Teraoka T, Watanabe K, Arie T, Komatsu K (2017) Rapid sex identification method of spinach (Spinacia oleracea L.) in the vegetative stage using loop-mediated isothermal amplification. Planta 245: 221-226. https://doi.org/10.1007/s00425-016-2618-z

Gong XH et al (2018) Epidemiology, aetiology and seasonality of infectious diarrhoea in adult outpatients through active surveillance in Shanghai, China, 2012-2016: a cross-sectional study. BMJ open 8:e019699. https://doi.org/10. 1136/bmjopen-2017-019699

Honda T, Ni YX, Miwatani T (1988) Purification and characterization of a hemolysin produced by a clinical isolate of Kanagawa phenomenon-negative Vibrio parahaemolyticus and related to the thermostable direct hemolysin. Infection and immunity 56:961-965

Jones MK, Oliver JD (2009) Vibrio vulnificus: disease and pathogenesis. Infection and immunity 77:1723-1733. https://doi.org/10.1128/iai.01046-08

Kumar BK, Raghunath P, Devegowda D, Deekshit VK, Venugopal MN, Karunasagar I, Karunasagar I (2011) Development of monoclonal antibody based sandwich ELISA for the rapid detection of pathogenic Vibrio parahaemolyticus in seafood. International journal of food microbiology 145 : 244-249. https://doi.org/10.1016/j.ijfoodmicro.2010.12.030

Law JW, Ab Mutalib NS, Chan KG, Lee LH (2015) Rapid methods for the detection of foodborne bacterial pathogens: principles, applications, advantages and limitations. Frontiers in microbiology 5:770. https://doi.org/10.3389/fmicb. 2014.00770

Lee LH, Ab Mutalib NS, Law JW, Wong SH, Letchumanan V (2018) Discovery on antibiotic resistance patterns of Vibrio parahaemolyticus in Selangor reveals carbapenemase producing Vibrio parahaemolyticus in marine and freshwater fish. Frontiers in microbiology 9:2513. https://doi.org/10.3389/fmicb.2018. 02513

Lesmana M, Subekti D, Simanjuntak CH, Tjaniadi P, Campbell JR, Oyofo BA (2001) Vibrio parahaemolyticus associated with cholera-like diarrhea among patients in North Jakarta, Indonesia. Diagnostic microbiology and infectious disease 39:71-75

Letchumanan V, Chan KG, Lee LH (2014) Vibrio parahaemolyticus: a review on the pathogenesis, prevalence, and advance molecular identification techniques. Frontiers in microbiology 5:705. https://doi.org/10.3389/fmicb.2014.00705

Li WW et al. (2018) Analysis of foodborne disease outbreaks in China mainland in 2013. Chinese Journal of Food Hygiene 30:293-298 doi:10.13590/j.cjfh.2018. 03.015

Li Y et al (2014) Vibrio parahaemolyticus, southern coastal region of China, 20072012. Emerging infectious diseases 20:685-688. https://doi.org/10.3201/ eid2004.130744

Liu Y et al (2015) A foodborne outbreak of gastroenteritis caused by Vibrio parahaemolyticus and norovirus through non-seafood vehicle. PloS one 10: e0137848. https://doi.org/10.1371/journal.pone.0137848

Martinez-Urtaza J, Baker-Austin C, Jones JL, Newton AE, Gonzalez-Aviles GD, DePaola A (2013) Spread of Pacific Northwest Vibrio parahaemolyticus strain. N Engl J Med 369:1573-1574. https://doi.org/10.1056/NEJMc1305535

Martinez-Urtaza J, Lozano-Leon A, Vina-Feas A, de Novoa J, Garcia-Martin O (2006) Differences in the API 20E biochemical patterns of clinical and environmental Vibrio parahaemolyticus isolates. FEMS microbiology letters 255:75-81. https://doi.org/10.1111/j.1574-6968.2005.00052.x

Martinez-Urtaza J et al (2016) Epidemiological investigation of a foodborne outbreak in Spain associated with U.S. West Coast genotypes of Vibrio parahaemolyticus. SpringerPlus 5:87. https://doi.org/10.1186/s40064-016-1728-1

McCarthy SA, DePaola A, Cook DW, Kaysner CA, Hill WE (1999) Evaluation of alkaline phosphatase- and digoxigenin-labelled probes for detection of the thermolabile hemolysin (t/h) gene of Vibrio parahaemolyticus. Lett Appl Microbiol 28:66-70

McLaughlin JB et al (2005) Outbreak of Vibrio parahaemolyticus gastroenteritis associated with Alaskan oysters. N Engl J Med 353:1463-1470. https://doi. org/10.1056/NEJMoa051594

Nair GB, Ramamurthy T, Bhattacharya SK, Dutta B, Takeda Y, Sack DA (2007) Global dissemination of Vibrio parahaemolyticus serotype O3:K6 and its serovariants. Clin Microbiol Rev 20:39-48. https://doi.org/10.1128/cmr.00025-06

Nishibuchi M, Kaper JB (1995) Thermostable direct hemolysin gene of Vibrio parahaemolyticus: a virulence gene acquired by a marine bacterium. Infection and immunity 63:2093-2099

Nishibuchi M, Taniguchi T, Misawa T, Khaeomanee-lam V, Honda T, Miwatani T (1989) Cloning and nucleotide sequence of the gene (trh) encoding the hemolysin related to the thermostable direct hemolysin of Vibrio parahaemolyticus. Infection and immunity 57:2691-2697

Nordin N, Yusof NA, Abdullah J, Radu S, Hushiarian R (2016) Sensitive detection of multiple pathogens using a single DNA probe. Biosens Bioelectron 86: 398-405. https://doi.org/10.1016/j.bios.2016.06.077

Notomi T, Okayama H, Masubuchi H, Yonekawa T, Watanabe K, Amino N, Hase T (2000) Loop-mediated isothermal amplification of DNA. Nucleic Acids Res 28:E63

Orata FD, Keim PS, Boucher Y (2014) The 2010 cholera outbreak in Haiti: how science solved a controversy. PLoS Pathog 10:e1003967. https://doi.org/10. 1371/journal.ppat.1003967

Ottaviani D et al (2012) Nontoxigenic Vibrio parahaemolyticus strains causing acute gastroenteritis. Journal of clinical microbiology 50:4141-4143. https:// doi.org/10.1128/jcm.01993-12

Park KS, Ono T, Rokuda M, Jang MH, Okada K, lida T, Honda T (2004) Functional characterization of two type III secretion systems of Vibrio parahaemolyticus. Infection and immunity 72:6659-6665. https://doi.org/10.1128/iai.72.11.66596665.2004

Park MS, Park KH, Bahk GJ (2018) Interrelationships between multiple climatic factors and incidence of foodborne diseases. International journal of environmental research and public health 15. https://doi.org/10.3390/ ijerph15112482

Poon LL et al (2004) Rapid detection of the severe acute respiratory syndrome (SARS) coronavirus by a loop-mediated isothermal amplification assay. Clin Chem 50:1050-1052. https://doi.org/10.1373/clinchem.2004.032011

Twedt RM (1989) Vibrio parahaemolyticus. In: Doyle MP (ed) Foodborne bacterial pathogens. Marcel Dekker Inc., New York, pp 552-4.

Raszl SM, Froelich BA, Vieira CR, Blackwood AD, Noble RT (2016) Vibrio parahaemolyticus and Vibrio vulnificus in South America: water, seafood and human infections. Journal of applied microbiology 121:1201-1222. https:// doi.org/10.1111/jam.13246

Rince $A$ et al (2018) Occurrence of bacterial pathogens and human noroviruses in shellfish-harvesting areas and their catchments in France. Frontiers in microbiology 9:2443. https://doi.org/10.3389/fmicb.2018.02443

Rizvi AV, Bej AK (2010) Multiplexed real-time PCR amplification of th, tdh and trh genes in Vibrio parahaemolyticus and its rapid detection in shellfish and Gulf of Mexico water. Antonie van Leeuwenhoek 98:279-290. https://doi.org/10. 1007/s10482-010-9436-2

Rosche TM, Yano Y, Oliver JD (2005) A rapid and simple PCR analysis indicates there are two subgroups of Vibrio vulnificus which correlate with clinical or environmental isolation. Microbiol Immunol 49:381-389

Tada J et al (1992) Detection of the thermostable direct hemolysin gene (tdh) and the thermostable direct hemolysin-related hemolysin gene (trh) of Vibrio parahaemolyticus by polymerase chain reaction. Mol Cell Probes 6:477-487

Taniguchi H, Kubomura S, Hirano H, Mizue K, Ogawa M, Mizuguchi Y (1990) Cloning and characterization of a gene encoding a new thermostable hemolysin from Vibrio parahaemolyticus. FEMS microbiology letters 55: 339-345

Taniguchi H, Ohta H, Ogawa M, Mizuguchi Y (1985) Cloning and expression in Escherichia coli of Vibrio parahaemolyticus thermostable direct hemolysin and thermolabile hemolysin genes. Journal of bacteriology 162:510-515 
Tsai SE, Jong KJ, Tey YH, Yu WT, Chiou CS, Lee YS, Wong HC (2013) Molecular characterization of clinical and environmental Vibrio parahaemolyticus isolates in Taiwan. International journal of food microbiology 165:18-26. https://doi. org/10.1016/j.jifoodmicro.2013.04.017

Tsunasawa S, Sugihara A, Masaki T, Sakiyama F, Takeda Y, Miwatani T, Narita K (1987) Amino acid sequence of thermostable direct hemolysin produced by Vibrio parahaemolyticus. J Biochem 101:111-121

Wang Y, Li D, Wang Y, Li K, Ye C (2016) Rapid and sensitive detection of Vibrio parahaemolyticus and Vibrio vulnificus by multiple endonuclease restriction real-time loop-mediated isothermal amplification. Technique Molecules (Basel, Switzerland) 21:E111. https://doi.org/10.3390/molecules21010111

Waterfield T, Fairley D, Lynn F, Blackwood B, Shields MD (2018) A protocol for a systematic review of the diagnostic accuracy of Loop-mediated-isothermal AMPlification (LAMP) in diagnosis of invasive meningococcal disease in children. Systematic reviews 7:86. https://doi.org/10.1186/s13643-018-0747-0

Wong YP, Othman S, Lau YL, Radu S, Chee HY (2018) Loop-mediated isothermal amplification (LAMP): a versatile technique for detection of micro-organisms. Journal of applied microbiology 124:626-643. https://doi.org/10.1111/jam. 13647

Xu D, Ji L, Wu X, Yan W, Chen L (2018) Detection and differentiation of Vibrio parahaemolyticus by multiplexed real-time PCR. Canadian journal of microbiology 64:809-815. https://doi.org/10.1139/cjm-2018-0083

Yang JH et al (2017a) Distribution and antimicrobial susceptibility of Vibrio species associated with zooplankton in coastal area of Korea. Mar Pollut Bull 125:39-44. https://doi.org/10.1016/j.marpolbul.2017.07.054

Yang Y, Xie J, Li H, Tan S, Chen Y, Yu H (2017b) Prevalence, antibiotic susceptibility and diversity of Vibrio parahaemolyticus isolates in seafood from South China. Frontiers in microbiology 8:2566. https://doi.org/10.3389/fmicb. 2017.02566

Yi MY et al (2014) Real time loop-mediated isothermal amplification using a portable fluorescence scanner for rapid and simple detection of Vibrio parahaemolyticus. Food Control 41:91-95. https://doi.org/10.1016/j.foodcont. 2014.01.005

Zhang Z, Lou Y, Du S, Xiao L, Niu B, Pan Y, Zhao Y (2017) Prevalence of Vibrio parahaemolyticus in seafood products from hypermarkets in Shanghai. J Sci Food Agric 97:705-710. https://doi.org/10.1002/jsfa.7715

Zhou S, Gao ZX, Zhang M, Liu DY, Zhao XP, Liu Y (2016) Development of a quadruplex loop-mediated isothermal amplification assay for field detection of four Vibrio species associated with fish disease. SpringerPlus 5:1104. https://doi.org/10.1186/s40064-016-2760-x

\section{Publisher's Note}

Springer Nature remains neutral with regard to jurisdictional claims in published maps and institutional affiliations.

Ready to submit your research? Choose BMC and benefit from:

- fast, convenient online submission

- thorough peer review by experienced researchers in your field

- rapid publication on acceptance

- support for research data, including large and complex data types

- gold Open Access which fosters wider collaboration and increased citations

- maximum visibility for your research: over $100 \mathrm{M}$ website views per year

At $\mathrm{BMC}$, research is always in progress.

Learn more biomedcentral.com/submissions 